\title{
Design of Robust Controller using Neural Network and Sliding Mode
}

\author{
Min Chan Kim, Tae Kue Kim, Seung Kyu Park, Gun Pyong Kwak, Ho Kyun Ahn and \\ Tae Sung Yoon, Member, KIMICS
}

\begin{abstract}
This paper derives a nominal state relationship (NSR) from the data of a nominal system. Through an example of a second order system, it is shown that the relationship can be derived only in the system with different real eigenvalues. In higher order system, the relationship is expressed by using neural network (NN). The derived NSR is used to design a noble sliding surface with a nominal system characteristic. By using the sliding surface, the robustness of the sliding mode control (SMC) is added to the poleplacement control.
\end{abstract}

Index Terms - Nominal state relationship, Pole placement control, Sliding mode, Neural network.

\section{INTRODUCTION}

Sliding mode control can be used to improve the robustness of systems [1-4]. It is desirable that the SMC robustness is added to the other control system besides SMC. However, conventional SMC cannot provide its robustness to the other control method. For example, SMC cannot be used with pole-placement control. Linearly dependency of states in sliding function makes the control system have the number of poles less than the original one [5]. This means that the SMC dynamic cannot have the characteristics of the nominal control system controlled by pole placement. By defining an augmented system with an additional state, a special sliding surface which can have nominal system characteristics was proposed in [5][6][7]. This paper proposes a very different sliding surface which uses the nominal states relationship (NSR). NSR is the relationship among the states in the nominal system which has desired characteristics. From an example of a second order system, we could guess that NSR is possible to obtain only in the system with different eigenvalues. Therefore, pole placement give only real different poles to a nominal system and then NSR is approximated by using neural network(NN) trained by using the states data of a nominal system. For the approximation, the very basic $\mathrm{NN}$ is used in this paper [8]. The derived NSR is used to define a sliding surface and SMC with this sliding surface shows

\footnotetext{
Manuscript received May 24, 2010; revised May 25, 2010; accepted June 7, 2010.

Min-Chan Kim is with the Department of Electrical Engineering, Changwon National University, Changwon, 641-773, Korea (Email: mchkim@changwon.ac.kr)
}

that the sliding surface has the nominal control system characteristic. The pole placement with this SMC shows robustness for uncertain systems. This paper is organized as follows. In Section 2, a conventional sliding function and its problem is described. The NSR is obtained in section 3. In Section 4, noble sliding surface is designed by using the NSR. In Section 5, numerical example and computer simulations are carried out to verify the NSR and the robustness of the pole placement with the SMC proposed in this paper. Finally, some conclusions are presented in Section 6.

\section{PROBLEM FORMULATION}

Consider the following $\mathrm{n}$-th order system with parameter uncertainty and unknown disturbance.

$$
\dot{\mathrm{x}}(\mathrm{t})=(\mathrm{A}+\Delta \mathrm{A}) \mathrm{x}(\mathrm{t})+\mathrm{Bu}(\mathrm{t})+\mathrm{Df}(\mathrm{t})
$$

where $\mathrm{x} \in \mathrm{R}^{\mathrm{n}}$ is the system states, $\mathrm{u} \in \mathrm{R}^{\mathrm{m}}$ is the control input, $\mathrm{f} \in \mathrm{R}^{\mathrm{r}}$ is the unknown disturbance. And the bounded uncertainties $\Delta \mathrm{A}$ and the disturbance matrix $\mathrm{D}$ satisfy the following matching condition.

$$
\operatorname{rank}([\mathrm{B}: \Delta \mathrm{A}: \mathrm{D}])=\operatorname{rank} \mathrm{B}
$$

With the above condition, the uncertainties and disturbance can be expressed as

$$
\begin{aligned}
& \Delta \mathrm{A} x(\mathrm{t})=\mathrm{B} \Delta \mathrm{A}_{1} \mathrm{x}(\mathrm{t}) \\
& \mathrm{D} \mathrm{f}(\mathrm{t})=\mathrm{BD}_{1} \mathrm{f}(\mathrm{t})
\end{aligned}
$$

The system (1) can be expressed as

$$
\dot{x}(t)=A x(t)+B u(t)+B h(t)
$$

where $\mathbf{h}(t)=\Delta \mathbf{A}_{\mathbf{1}} \mathbf{x}(t)+\mathbf{D}_{\mathbf{1}} \mathbf{f}(t)$ is lumped uncertainty and norm bounded as $\|\mathbf{h}\|\left\langle\mathbf{h}_{\max }\right.$.

For the above system, the nominal system is as follows.

$$
\dot{\mathrm{x}}(\mathrm{t})=\mathrm{Ax}(\mathrm{t})+\mathrm{Bu}_{0}(\mathrm{t})
$$

Regulator problem with feedback control input $\mathrm{u}_{0}(t)=-\mathbf{K} \mathbf{x}(t)$ can be described as follows. 


$$
\dot{\mathrm{x}}(\mathrm{t})=(\mathrm{A}-\mathrm{BK}) \mathrm{x}(\mathrm{t})
$$

The above system has desired characteristics. The relationship between the states is obtained and used to design sliding surface. In the conventional SMC, the sliding surface cannot have nominal characteristics because of the linearly dependent property of the states as follows.

$$
\mathrm{s}=\mathrm{c}_{1} \mathrm{x}_{1}(\mathrm{t})+\mathrm{c}_{2} \mathrm{x}_{2}(\mathrm{t})+\cdots+\mathrm{c}_{\mathrm{n}} \mathrm{x}_{\mathrm{n}}(\mathrm{t})=0
$$

where the coefficients $c_{n}, c_{n-1}, \cdots \cdot \cdot, c_{2}, c_{1}$ are chosen to guarantee the stability of sliding mode dynamics.

In the reference [7], the SMC with virtual stats was developed. Including virtual state, a sliding surface is designed for augmented system and has nominal system characteristics. In the case of using this sliding surface, the order of controller becomes higher compared to the SMC proposed in this paper.

The problem to be solved in this paper is to obtain the relationship of the states belonged to the system and to use it to determine sliding surface.

\section{DERIVATION NSR}

In the second order system with different real eigenvalues, it is easy to obtain the relationship among the system states.

Consider the following second-order system.

$$
\dot{x}(t)=\left[\begin{array}{cc}
\lambda_{1} & 0 \\
0 & \lambda_{2}
\end{array}\right] \mathrm{x}(\mathrm{t})
$$

The solutions are as follows.

$$
\begin{aligned}
& x_{1}(t)=e^{\lambda_{1} t} x_{1}(0) \\
& x_{2}(t)=e^{\lambda_{2} t} x_{2}(0)
\end{aligned}
$$

The above equation is changed as follows.

$$
\mathrm{x}_{\mathrm{n}_{1}}^{\lambda_{2}}=\mathrm{x}_{\mathrm{n}_{2}}^{\lambda_{1}}
$$

where $x_{n_{1}}^{\lambda_{2}}=\left(\frac{x_{1}(t)}{x_{1}(0)}\right)^{\lambda}$ and $x_{n_{2}}^{\lambda_{1}}=\left(\frac{x_{2}(t)}{x_{2}(0)}\right)^{\lambda 1}$.

The above condition is called as nominal states relationship in this paper. By using (10), a novel nonlinear sliding surface which has the characteristics of nominal system will be proposed.

In the case of complex conjugate eigenvalues, the diagonalization is achieved as follows.

$$
\dot{x}(t)=\left[\begin{array}{rr}
\sigma & \omega \\
-\omega & \sigma
\end{array}\right] x(t)
$$

The solutions are as follows.

$$
\begin{aligned}
& x_{1}(t)=e^{\sigma t}\left(\cos (w t) x_{1}(0)+\sin (w t) x_{2}(0)\right) \\
& x_{2}(t)=e^{\sigma t}\left(\cos (w t) x_{2}(0)-\sin (w t) x_{1}(0)\right)
\end{aligned}
$$

From (12), the following equation is obtained.

$$
\mathrm{x}_{1}^{2}(\mathrm{t})+\mathrm{x}_{2}^{2}(\mathrm{t})=\mathrm{e}^{2 \sigma \mathrm{t}}\left(\mathrm{x}_{1}^{2}(0)+\mathrm{x}_{2}^{2}(0)\right)
$$

The relationship (13) shows that the state relationship cannot be described independently on the initial values. Therefore, we can conclude that the state relationships of the systems with only different real eigenvalues can be described as states variables. However, the relationship is not easy to be derived in a higher order system. So, in this paper, the following $\mathrm{NN}$ is used to describe the states relationship of higher order system as in the Fig. 1.

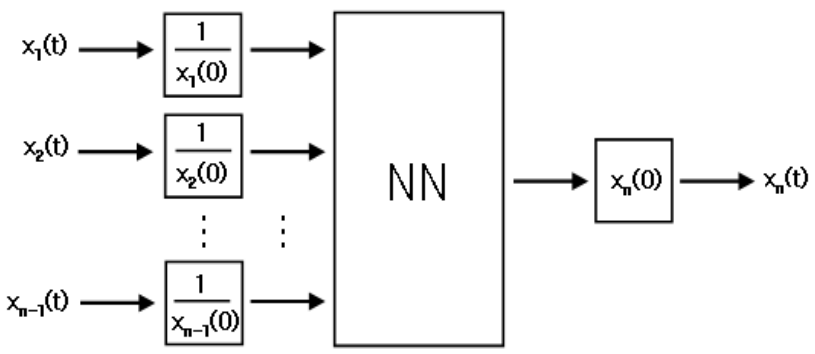

Fig. 1. NN block in NSR.

The type of NN used in this paper is the feed-forward multilayer NN, which is shown in the Fig. 2.

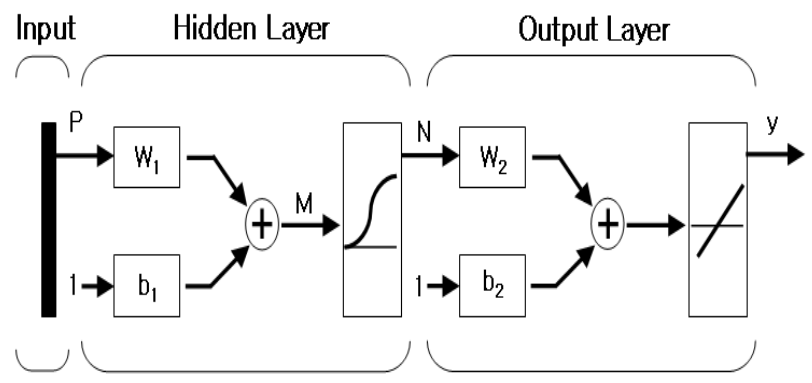

Fig. 2. Structure of NN.

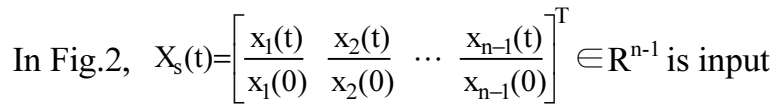


vector, $\frac{\mathrm{x}_{\mathrm{n}}(\mathrm{t})}{\mathrm{x}_{\mathrm{n}}(0)} \in \mathrm{R}$ is target vector and $\mathrm{k}$ is the number of hidden layers, $\mathrm{W}_{1} \in \mathrm{R}^{\mathrm{k} \times \mathrm{p}}$ is hidden layer's weights, $\mathrm{b}_{1} \in \mathrm{R}^{\mathrm{k}}$ is the hidden layer bias, $\mathrm{W}_{2} \in \mathrm{R}^{1 \times \mathrm{k}}$ and $\mathrm{b}_{2} \in \mathrm{R}$ are weights of the output layer and bias respectively.

Through the NN, a NSR can be described as follows.

$$
\frac{x_{n}(t)}{x_{n}(0)}=W_{2} N(t)+b_{2}
$$

where

$$
\begin{aligned}
& \mathrm{N}(\mathrm{t})=\operatorname{logsig}(\mathrm{M}(\mathrm{t}))=\left[\begin{array}{c}
\frac{1}{1+\mathrm{e}^{-\left(\mathrm{m}_{1}(\mathrm{t})+\mathrm{b}_{1(1)}\right)}} \\
\frac{1}{1+\mathrm{e}^{-\left(\mathrm{m}_{2}(\mathrm{t})+\mathrm{b}_{1(2)}\right)}} \\
\vdots \\
\frac{1}{1+\mathrm{e}^{-\left(\mathrm{m}_{\mathrm{k}}(\mathrm{t})+\mathrm{b}_{1(\mathrm{k})}\right)}}
\end{array}\right]=\left[\begin{array}{c}
\mathrm{n}_{1}(\mathrm{t}) \\
\mathrm{n}_{2}(\mathrm{t}) \\
\vdots \\
\mathrm{n}_{\mathrm{k}}(\mathrm{t})
\end{array}\right] \\
& \mathrm{M}(\mathrm{t})=\mathrm{W}_{1} \mathrm{X}_{\mathrm{s}}(\mathrm{t})+\mathrm{b}_{1}, \\
& =\left[\begin{array}{ccc}
W_{1(1,1)} \frac{x_{1}(t)}{x_{1}(0)}+W_{1(1,2)} \frac{x_{2}(t)}{x_{2}(0)}+\cdots+W_{1(1, n-1)} & \frac{x_{n-1}(t)}{x_{n-1}(0)} \\
W_{1(2,1)} \frac{x_{1}(t)}{x_{1}(0)}+W_{1(2,2)} & \frac{x_{2}(t)}{x_{2}(0)}+\cdots+W_{1(2, n-1)} & \frac{x_{n-1}(t)}{x_{n-1}(0)} \\
\vdots & \\
W_{1(k, 1)} \frac{x_{1}(t)}{x_{1}(0)}+W_{l_{(k, 2)}} \frac{x_{2}(t)}{x_{2}(0)}+\cdots+W_{1(k, n-1)} & \frac{x_{n-1}(t)}{x_{n-1}(0)}
\end{array}\right] \\
& +\left[\begin{array}{c}
b_{11} \\
b_{12} \\
\vdots \\
b_{1 k}
\end{array}\right]=\left[\begin{array}{c}
m_{1}(t)+b_{11} \\
m_{2}(t)+b_{12} \\
\vdots \\
m_{k}(t)+b_{1 k}
\end{array}\right]
\end{aligned}
$$

$\mathbf{W}_{\mathbf{1}(\mathrm{i}, \mathrm{j})}$ is a matrix $\mathrm{W}_{1}$ with the $\mathrm{i}$-th row and the $\mathrm{j}$-th column, $\mathbf{b}_{\mathbf{1}_{\mathrm{i}}}$ is a the $\mathrm{i}$-th element of the vector $\mathbf{b}_{\mathbf{1}}$.

Back propagation method is used for training by using the data from the states of nominal control system with the following state feedback control.

$$
\mathrm{u}_{0}(\mathrm{t})=-\mathrm{K} x(\mathrm{t})
$$

The trained $\mathrm{NN}$ will be used for designing sliding surface and the sliding surface can have pole-placement control performance.

\section{SLIDING SURFACE DESIGN WITH TRAINED NN}

The relationship of nominal states in the state feedback control system, the system (1) is approximated as (14).

By using the nonlinear relationship between the states in (14), a novel sliding surface is proposed as follows.

$$
\mathrm{s}=\frac{\mathrm{x}_{\mathrm{n}}(\mathrm{t})}{\mathrm{x}_{\mathrm{n}}(0)}-\left(\mathrm{W}_{2} \mathrm{~N}(\mathrm{t})+\mathrm{b}_{2}\right)
$$

Differentiating $\mathrm{W}_{2} \mathrm{~N}(\mathrm{t})$ such as (14) with respect to time, the following equation can be obtained.

$$
\begin{aligned}
& W_{2} \frac{d N(t)}{d t}=W_{21} \frac{d n_{1}(t)}{d t}+W_{22} \frac{d n_{2}(t)}{d t}+\cdots+W_{2 k} \frac{d n_{k}(t)}{d t} \\
& =W_{21} \frac{\partial n_{1}(t)}{\partial x_{1}(t)} \frac{\partial x_{1}(t)}{\partial t}+W_{21} \frac{\partial n_{1}(t)}{\partial x_{2}(t)} \frac{\partial x_{2}(t)}{\partial t}+\cdots+W_{21} \frac{\partial n_{1}(t)}{\partial x_{n-1}(t)} \frac{\partial x_{n-1}(t)}{\partial t} \\
& +W_{22} \frac{\partial n_{2}(t)}{\partial x_{1}(t)} \frac{\partial x_{1}(t)}{\partial t}+W_{2} \frac{\partial n_{2}(t)}{\partial x_{2}(t)} \frac{\partial x_{2}(t)}{\partial t}+\cdots+W_{2} \frac{\partial n_{2}(t)}{\partial x_{n-1}(t)} \frac{\partial x_{n-1}(t)}{\partial t} \\
& +\cdots+W_{2 k} \frac{\partial n_{k}(t)}{\partial x_{1}(t)} \frac{\partial x_{1}(t)}{\partial t}+W_{2 k} \frac{\partial n_{k}(t)}{\partial x_{2}(t)} \frac{\partial x_{2}(t)}{\partial t}+\cdot \cdot+W_{2 k} \frac{\partial n_{k}(t)}{\partial x_{n-1}(t)} \frac{\partial x_{n-1}(t)}{\partial t} \\
& =\sum_{i=1}^{n-1} \sum_{j=1}^{k} W_{2 j} \frac{-W_{1(j, i)}}{\left(1+e^{-\left(m_{j}(t)+b_{1 j}\right)}\right)^{2}} \frac{\left.e_{i}(t)+b_{1 j}\right)}{x_{i}(0)}=\sum_{i=1}^{n-1} W_{i} \frac{x_{i}(t)}{x_{i}(0)}
\end{aligned}
$$

For the ease of calculation, let's consider the following controllable canonical form of the nominal system (5).

$$
\mathrm{A}=\left[\begin{array}{ccccc}
0 & 1 & 0 & \cdots & 0 \\
0 & 0 & 1 & \cdots & 0 \\
\vdots & \vdots & \vdots & \ddots & \vdots \\
0 & 0 & 0 & \cdots & 1 \\
-\alpha_{1} & -\alpha_{2} & -\alpha_{3} & \cdots & -\alpha_{\mathrm{n}}
\end{array}\right] \quad, \quad \mathrm{B}=\left[\begin{array}{c}
0 \\
0 \\
0 \\
\vdots \\
1
\end{array}\right]
$$

Then (17) may be written as

$$
\frac{\dot{x}_{n}(t)}{x_{n}(0)}=W X_{r}(t)
$$

where

$$
\mathrm{W}=\left[\overline{\mathrm{W}}_{1} \overline{\mathrm{W}}_{2} \cdots \overline{\mathrm{W}}_{\mathrm{n}-1}\right], \mathrm{X}_{\mathrm{r}}(\mathrm{t})=\left[\begin{array}{llll}
\frac{\mathrm{x}_{2}(\mathrm{t})}{\mathrm{x}_{1}(0)} & \frac{\mathrm{x}_{3}(\mathrm{t})}{\mathrm{x}_{2}(0)} & \cdots & \frac{\mathrm{x}_{\mathrm{n}}(\mathrm{t})}{\mathrm{x}_{\mathrm{n}-1}(0)}
\end{array}\right]^{\mathrm{T}} .
$$

To make the state stays on the sliding surface, the following hitting condition must be satisfied as follows.

$$
\mathrm{s} \dot{\mathrm{s}}=\mathrm{s}\left(\frac{1}{\mathrm{x}_{\mathrm{n}}(0)}\left(\sum_{\mathrm{i}=1}^{\mathrm{n}}-\alpha_{\mathrm{i}} \mathrm{x}_{\mathrm{i}}+\mathrm{u}(\mathrm{t})+\mathrm{h}(\mathrm{t})\right)-\mathrm{W} \mathrm{X}_{\mathrm{r}}(\mathrm{t})\right)<0
$$

For the above condition, the sliding mode control input which can force the state of the system onto the proposed sliding surface such as (16) is given by

$$
u(t)=x_{n}(0) \cdot W X_{r}(t)-\sum_{i=1}^{n}-\alpha_{i} x_{i}-h_{\max }(t) \operatorname{sgn}(s)
$$


where $h_{\max }$ is a upper bounded value of $h(t)$ and $\operatorname{sgn}(\mathrm{s})$ is a signum function.

\section{NUMERICAL EXAMPLE AND SIMULATION RESULTS}

To show the performance of the proposed sliding mode controller, consider the following third-order system.

$$
\left[\begin{array}{l}
\dot{x}_{1}(t) \\
\dot{x}_{2}(t) \\
\dot{x}_{3}(t)
\end{array}\right]=\left[\begin{array}{ccc}
0 & 1 & 0 \\
0 & 0 & 1 \\
-1 & -2 & -3
\end{array}\right]\left[\begin{array}{l}
\mathrm{x}_{1}(\mathrm{t}) \\
\mathrm{x}_{2}(\mathrm{t}) \\
\mathrm{x}_{3}(\mathrm{t})
\end{array}\right]+\left[\begin{array}{l}
0 \\
0 \\
1
\end{array}\right] \mathrm{u}(\mathrm{t})+\left[\begin{array}{l}
0 \\
0 \\
1
\end{array}\right] \mathrm{h}(\mathrm{t})
$$

where $\quad \mathrm{u}(\mathrm{t})=\mathrm{u}_{0}(\mathrm{t})+\mathrm{u}_{\mathrm{SMC}}(\mathrm{t}), \quad \mathrm{h}(\mathrm{t})=0.5 \sin (5 \mathrm{t}) \quad$ and $\mathbf{x}(0)=\left[\begin{array}{lll}3 & 2 & 1\end{array}\right]^{\mathrm{T}}$.

The eigenvalues of the following canonical system are $1,-2$ and -3 by nominal control input $\mathrm{u}_{0}(\mathrm{t})$.

$$
\left[\begin{array}{l}
\dot{x}_{1}(t) \\
\dot{x}_{2}(t) \\
\dot{x}_{3}(t)
\end{array}\right]=\left[\begin{array}{ccc}
0 & 1 & 0 \\
0 & 0 & 1 \\
-1 & -2 & -3
\end{array}\right]\left[\begin{array}{l}
x_{1}(t) \\
x_{2}(t) \\
x_{3}(t)
\end{array}\right]+\left[\begin{array}{l}
0 \\
0 \\
1
\end{array}\right] \mathrm{u}_{0}(t)
$$

where $\mathrm{u}_{0}(\mathrm{t})=-\mathrm{Kx}(\mathrm{t})$ and $\mathrm{K}=\left[\begin{array}{lll}5 & 9 & 3\end{array}\right]$.

Diagonalization is achieved as follows.

$$
\left[\begin{array}{l}
\dot{z}_{1}(t) \\
\dot{z}_{2}(t) \\
\dot{z}_{3}(t)
\end{array}\right]=\left[\begin{array}{ccc}
-1 & 0 & 0 \\
0 & -2 & 0 \\
0 & 0 & -3
\end{array}\right]\left[\begin{array}{l}
z_{1}(t) \\
z_{2}(t) \\
z_{3}(t)
\end{array}\right]+\left[\begin{array}{l}
-0.87 \\
-4.58 \\
-4.77
\end{array}\right] u_{S M d}(t)+\left[\begin{array}{l}
-0.87 \\
-4.58 \\
-4.77
\end{array}\right] \mathrm{h}(\mathrm{t})
$$

where

$$
\mathbf{z}(t)=\mathbf{P}^{-1} \mathbf{x}(t), \mathbf{P}=\left[\begin{array}{ccc}
-0.5774 & 0.2182 & -0.1048 \\
0.5774 & -0.4364 & 0.3145 \\
-0.5774 & 0.8729 & -0.9435
\end{array}\right] .
$$

Training data is obtained from the following nominal system by simulation.

$$
\left[\begin{array}{l}
\dot{\mathrm{z}}_{1}(\mathrm{t}) \\
\dot{\mathrm{z}}_{2}(\mathrm{t}) \\
\dot{\mathrm{z}}_{3}(\mathrm{t})
\end{array}\right]=\left[\begin{array}{ccc}
-1 & 0 & 0 \\
0 & -2 & 0 \\
0 & 0 & -3
\end{array}\right]\left[\begin{array}{l}
\mathrm{z}_{1}(\mathrm{t}) \\
\mathrm{z}_{2}(\mathrm{t}) \\
\mathrm{z}_{3}(\mathrm{t})
\end{array}\right]
$$

where the input vector is $\left[\begin{array}{l}z_{1}(t) \\ z_{2}(t)\end{array}\right]$ and the target vector is $\mathrm{Z}_{3}(\mathrm{t})$

For the system such as (25), the hidden layer's neurons are chosen as $\mathrm{k}=10$.

In the NN structure, weights and bias in two layers are given as $\mathrm{W}_{1} \in \mathrm{R}^{10 \times 2}, \mathrm{~b}_{1} \in \mathrm{R}^{10 \times 1}, \mathrm{~W}_{2} \in \mathrm{R}^{1 \times 10}$ and $\mathrm{b}_{2} \in \mathrm{R}$.

Training is carried out 8794 times. And the result of training performance is shown in Fig. 3.

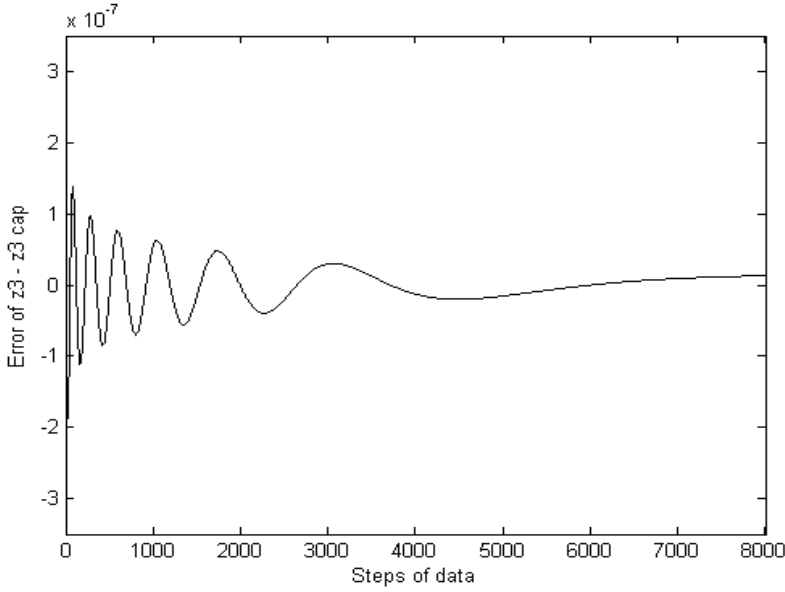

Fig. 3. Training performance of NN.

After training, the following weights and bias can be obtained.

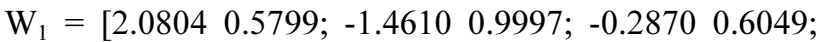
$-0.82990 .2561 ;-1.2725-1.6830 ; 0.3170-0.6339 ; 0.5010$ $1.7531 ;-1.47561 .6222 ; 1.2402-0.6392 ;-0.06291 .5086]$

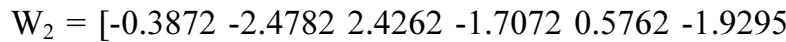
$-0.65142 .86461 .8755-0.5891]$

$$
\begin{aligned}
& \mathrm{b}_{1}=[0 ; 0 ; 0 ; 0 ; 0 ; 0 ; 0 ; 0 ; 0 ; 0] \\
& \mathrm{b}_{2}=0
\end{aligned}
$$

In this paper, using weights and bias such as (26), the proposed sliding surface is defined by

$$
s=\frac{z_{3}(t)}{z_{3}(0)}-\sum_{i=1}^{10} W_{2 i} n_{i}(t)=\frac{z_{3}(t)}{z_{3}(0)}-\sum_{i=1}^{10} W_{2 i} \frac{1}{1+e^{-m_{i}(t)}}
$$

$$
\text { where } \sum_{i=1}^{10} \mathrm{~m}_{\mathrm{i}}(\mathrm{t})=\left[\begin{array}{c}
\mathrm{W}_{1(1,1)} \frac{\mathrm{z}_{1}(\mathrm{t})}{\mathrm{z}_{1}(0)}+\mathrm{W}_{1(1,2)} \frac{\mathrm{z}_{2}(\mathrm{t})}{\mathrm{z}_{2}(0)} \\
\mathrm{W}_{1(2,1)} \frac{\mathrm{z}_{1}(\mathrm{t})}{\mathrm{z}_{1}(0)}+\mathrm{W}_{1(2,2)} \frac{\mathrm{z}_{2}(\mathrm{t})}{\mathrm{z}_{2}(0)} \\
\vdots \\
\mathrm{W}_{1(10,1)} \frac{\mathrm{z}_{1}(\mathrm{t})}{\mathrm{z}_{1}(0)}+\mathrm{W}_{1(10,2)} \frac{\mathrm{z}_{2}(\mathrm{t})}{\mathrm{z}_{2}(0)}
\end{array}\right] \text {. }
$$

Differentiating $\mathrm{S}$ with respect to time, the following equation can be obtained.

$$
\begin{aligned}
\mathrm{s} \dot{\mathrm{s}}= & \mathrm{s}\left(\frac{\dot{\mathrm{z}}_{3}(\mathrm{t})}{\mathrm{z}_{3}(0)}-\sum_{\mathrm{i}=1}^{2} \sum_{j=1}^{10} \mathrm{~W}_{2 \mathrm{j}} \frac{-\mathrm{W}_{1(\mathrm{j}, \mathrm{j})} \mathrm{e}^{-\mathrm{m}_{\mathrm{j}}(\mathrm{t})}}{\left(1+\mathrm{e}^{-\mathrm{m}_{\mathrm{j}}(\mathrm{t})}\right)^{2}} \frac{\dot{\mathrm{z}}_{\mathrm{i}}(\mathrm{t})}{\mathrm{z}_{\mathrm{i}}(0)}\right) \\
=\mathrm{s} & \left(\frac{\dot{\mathrm{z}}_{3}(\mathrm{t})}{\mathrm{z}_{3}(0)}-\sum_{\mathrm{j}=1}^{10} \mathrm{~W}_{2 \mathrm{j}} \frac{-\mathrm{W}_{1(\mathrm{j}, 1)} \mathrm{e}^{-\mathrm{m}_{\mathrm{j}}(\mathrm{t})}}{\left(1+\mathrm{e}^{-\mathrm{m}_{\mathrm{j}}(\mathrm{t})}\right)^{2}} \frac{\dot{\mathrm{z}}_{1}(\mathrm{t})}{\mathrm{z}_{1}(0)}\right. \\
& \left.-\sum_{\mathrm{j}=1}^{10} \mathrm{~W}_{2 \mathrm{j}} \frac{-\mathrm{W}_{1(\mathrm{j}, 2)} \mathrm{e}^{-\mathrm{m}_{\mathrm{j}}(\mathrm{t})}}{\left(1+\mathrm{e}^{-\mathrm{m}_{\mathrm{j}}(\mathrm{t})}\right)^{2}} \frac{\dot{\mathrm{z}}_{2}(\mathrm{t})}{\mathrm{z}_{2}(0)}\right)
\end{aligned}
$$




$$
\begin{aligned}
= & s\left(\frac{\dot{\mathrm{z}}_{3}(\mathrm{t})}{\mathrm{z}_{3}(0)}-\overline{\mathrm{W}}_{1} \frac{\dot{\mathrm{z}}_{1}(\mathrm{t})}{\mathrm{z}_{1}(0)}-\overline{\mathrm{W}}_{2} \frac{\dot{\mathrm{z}}_{2}(\mathrm{t})}{\mathrm{z}_{2}(0)}\right) \\
=\mathrm{s} & \left(\frac{\overline{\mathrm{W}}_{1}}{\mathrm{z}_{1}(0)} \mathrm{z}_{1}(\mathrm{t})+2 \frac{\overline{\mathrm{W}}_{2}}{\mathrm{z}_{2}(0)} \mathrm{z}_{2}(\mathrm{t})-\frac{3 \mathrm{z}_{3}(\mathrm{t})}{\mathrm{z}_{3}(0)}\right. \\
& +\left(\frac{-4.77}{\mathrm{z}_{3}(0)}+0.87 \frac{\overline{\mathrm{W}}_{1}}{\mathrm{z}_{1}(0)}+4.58 \frac{\overline{\mathrm{W}}_{2}}{\mathrm{z}_{2}(0)}\right) \mathrm{u}_{\mathrm{SMC}}(\mathrm{t}) \\
& \left.+\left(\frac{-4.77}{\mathrm{z}_{3}(0)}+0.87 \frac{\overline{\mathrm{W}}_{1}}{\mathrm{z}_{1}(0)}+4.58 \frac{\overline{\mathrm{W}}_{2}}{\mathrm{z}_{2}(0)}\right) \mathrm{h}(\mathrm{t})\right)
\end{aligned}
$$

From the above equation, the following sliding mode control input is constructed by

$$
\begin{aligned}
\mathrm{u}_{\mathrm{SMC}}(\mathrm{t})=\frac{1}{\overline{\mathrm{W}}} & \left(-\frac{\overline{\mathrm{W}}_{1}}{\mathrm{z}_{1}(0)} \mathrm{z}_{1}(\mathrm{t})-2 \frac{\overline{\mathrm{W}}_{2}}{\mathrm{z}_{2}(0)} \mathrm{z}_{2}(\mathrm{t})\right. \\
& +3 \frac{\mathrm{z}_{3}(\mathrm{t})}{\mathrm{z}_{3}(0)}-\mathrm{h}_{\max }(\mathrm{t}) \operatorname{sign}(\mathrm{s} \cdot \overline{\mathrm{W}})
\end{aligned}
$$

where $\overline{\mathrm{W}}=\frac{-4.77}{\mathrm{z}_{3}(0)}+0.87 \frac{\overline{\mathrm{W}}_{1}}{\mathrm{z}_{1}(0)}+4.58 \frac{\overline{\mathrm{W}}_{2}}{\mathrm{z}_{2}(0)}$ and $\mathrm{h}_{\max }=1.1$.

In (29), the input chattering is occurred. It causes an undesirable high frequency component in the state trajectory.

To solve this problem, the following saturation function can be obtained.

$$
\operatorname{sat}\left[\frac{\mathrm{s}}{\phi}\right]=\left\{\begin{array}{cc}
\frac{\mathrm{s}}{\phi} & \|\mathrm{s}\| \leq \varphi \\
\operatorname{sgn}(\mathrm{s}) & \|\mathrm{s}\|>\varphi
\end{array}\right.
$$

where $\phi$ is the boundary layer thickness neighboring the sliding surface.

The simulation results are shown as follows. The Fig. 4 shows that the convergence of the states. The state trajectories of the proposed SMC which has the same performance with the pole-placement control system without uncertainties. The proposed sliding surface and the proposed sliding mode control input are shown in Fig. 5 and Fig. 6 respectively.

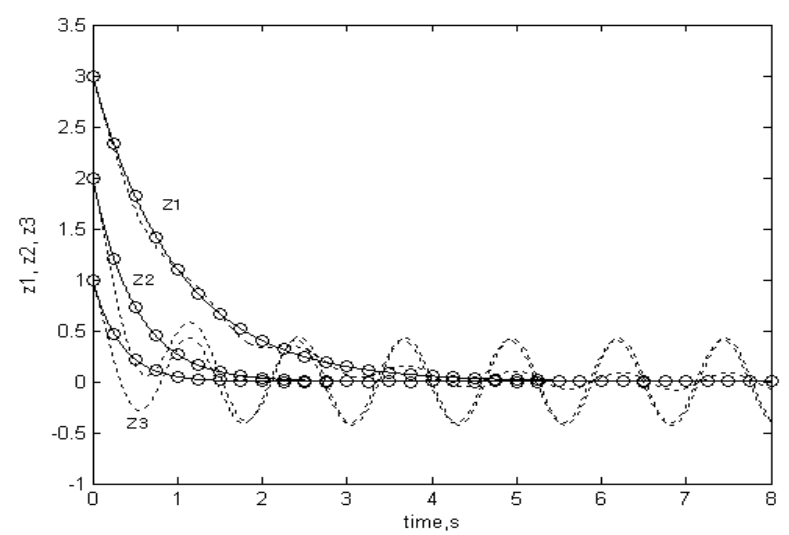

Fig. 4. State trajectories of the state feedback control and the proposed SMC with uncertainty.

—— state feedback control without uncertainty ------ state feedback control with uncertainty O proposed sliding mode control with uncertainty

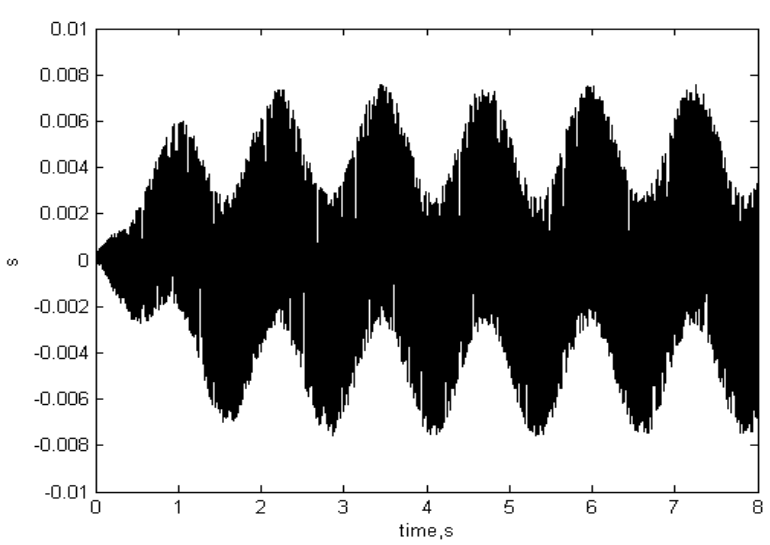

Fig. 5. Sliding surface of the proposed SMC.

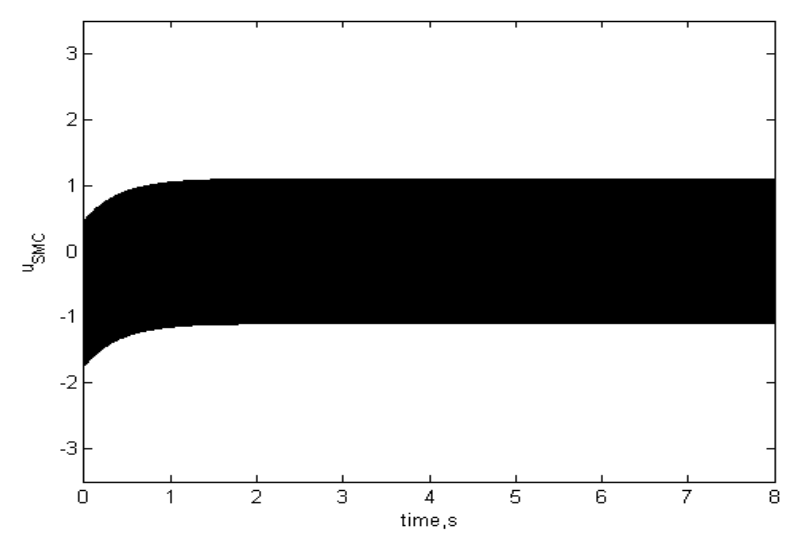

Fig. 6. Control input of the proposed SMC.

\section{CONCLUSIONS}

This paper derived the NSR of the system with different real eigenvalues by using NN. The NSR is used for designing sliding surface which can have the characteristics of a nominal system controlled by pole placement. The NSR of this paper is very useful for adding the robustness of SMC to other control methods besides SMC.

\section{ACKNOWLEDGMENT}

The authors of this paper were partly supported by the Second Stage of Brain Korea 21 Projects and Changwon National University in 2009

\section{REFERENCES}

[1] U. Itkis, Control systems of variable structure, JOHNWILLY \& SONS, 1976.

[2] V. I Utkin, Sliding modes and their application in variable structure systems, Mir Publishers, 1978. 
[3] J. Y. Hung, W. Gao, and J.C. Hung, "Variable structure control : A survey,", IEEE Trans. on Industrial Electronics, vol.40, no.1, pp. 2-22, February 1993

[4] K. D. Young, V. I. Utkin and U. Ozguner, "A control engineer's guide to sliding mode control," IEEE Trans. on Control Systems Technology, vol.7, no.3, pp. 328-342, May 1999.

[5] S. K. Park and H.K. Ahn, "Robust controller design with novel sliding surface-linear optimal control case," IEE Proceedings, Control Theory and Applications, vol.146, no.3, pp. 242-246, May 1999.

[6] Young Sam Song, Sung Ha Kwon, Seung Kyu Park, Eun Tae Jeung, "Sliding Mode Control for Time_delay System using a Virtual State," American Control Conference , Arlington USA, pp4669-4674, 2001.

[7] Seung Kyu Park, Ho Kyun Ahn, "Nonconservative Sliding Mode Control with the Feedback Linearization of Nonlinear System,", 39th IEEE Conference on Decision Control, Sydney, Australia, pp.2210-2211, 2000.

[8] Daniel Graupe, Principles of Artificial Neural Networks 2 ed. Advanced Series in Circuits and Systems - vol. 6, World Scientific Publishing Company, 2007.

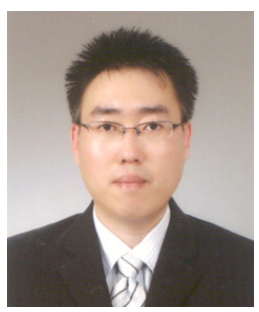

\section{Min-Chan Kim}

Received the B. S., M. S., and Ph. D. degrees in Electrical Engineering from Changwon National University in 1996, 1998 and 2003, respectively. From 2006 to 2009, he was a research professor under the Brain Korea 21 Project Corps and is currently research professor under the Human resource development center for Offshore and Plant Engineering(HOPE) at Changwon National University. His research interests include in the area of $\mathrm{H}_{\infty}$ robust control theory, sliding mode control theory, system identification and its applications.

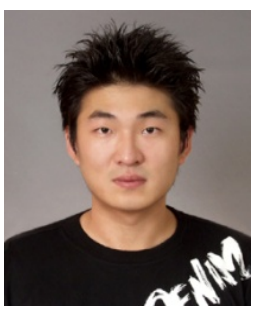

Tae-Kue Kim

Received the B. S., M. S. degrees in Electrical Engineering from Changwon National University in 2006,2008 , respectively. He is currently in Changwon National University for $\mathrm{Ph}$. D. degree. His research interests include in the area of nonlinear control, system identification, motion control, power electronics.

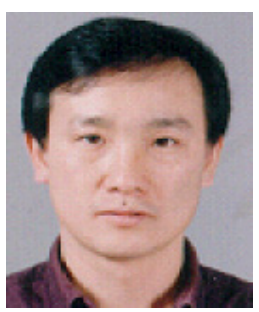

\section{Seung-Kyu Park}

Received the B. S., M. S., and Ph. D. degrees in Electrical Engineering from Korea University in 1984, 1986 and 1990, respectively. He was a visiting professor of Strathclyde University, England from 1995 to 1996 . Since 1990, he is currently a professor in the Department of Electrical Engineering at Changwon National University, Changwon, Korea. His research interests include in the area of adaptive control theory, robust control theory and nonlinear control theory.

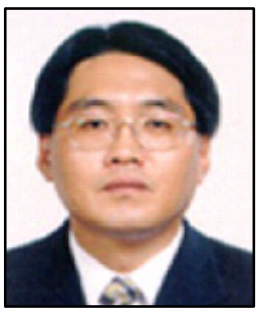

Gun-Pyong Kwak

Received the B. S., M. S., and Ph. D. degrees in Electrical Engineering from Korea University in 1982, 1985 and 1990, respectively. He was a section chief of CNC team, LGIS from 1990 to 1997. Since 1998 , he is currently a professor in the Department of Electrical Engineering at Changwon National University, Changwon, Korea. His research interests include in the area of control algorithm and motion controller.

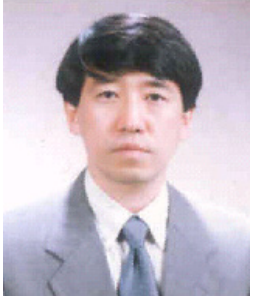

\section{Ho-Kyun Ahn}

Received the B. S., M. S., and Ph. D. degrees in Electrical Engineering from Korea University in 1980, 1988 and 1992, respectively. He was a chief of Electrical Design Team, Hanshin Construction from 1980 to 1986. Since 1992, he is currently a professor in the Department of Electrical Engineering at Changwon National University, Changwon, Korea. His research interests include in the area of power electronics, power conversion and alternative energy.

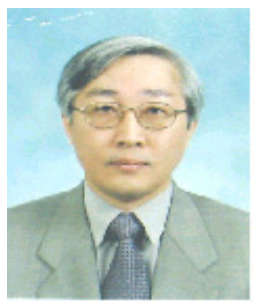

\section{Tae-Sung Yoon}

Received the B. S., M. S., and ph. D. degrees, in Electrical Engineering from Yonsei University, Seoul, Korea, in 1978, 1980 and 1988, respectively. He worked with the Department of Electrical Engineering at the 2nd Naval Academy, Jinhae, Korea, as a member of the teaching staff from 1980 to 1983 . He worked with the Department of Electrical Engineering at Vanderbilt University, Nashville, as a Visiting Assistant Professor from 1994 to 1995. Since 1989, he has been with the Department of Electrical Engineering, Changwon National University, Changwon, Korea where he is currently a Professor. His research interests include robust filtering and mobile robotics. 